\title{
Optics outreach activities: measuring learning outcomes
}

\section{Guillermo Sánchez-Guerrero, Perla Viera-González}

Guillermo E. Sánchez-Guerrero, Perla M. Viera-González, "Optics outreach activities: measuring learning outcomes," Proc. SPIE 10741, Optics Education and Outreach V, 107410N (14 September 2018); doi: 10.1117/12.2320330

SPIE Event: SPIE Optical Engineering + Applications, 2018, San Diego, California, United States 


\title{
Optics outreach activities: measuring learning outcomes
}

\author{
Guillermo E. Sánchez-Guerrero ${ }^{\mathrm{a}}$ and Perla M. Viera-González ${ }^{\mathrm{a}}$ \\ ${ }^{a}$ Facultad de Ciencias Físico Matemáticas, Universidad Autonoma de Nuevo Leon, Av. \\ Universidad S/N Ciudad Universitaria, San Nicolás de los Garza, México
}

\begin{abstract}
The objective of this work is present diverse ways to measure the impact and quality of the informal optics education activities for its improvement in content, quality and didactic techniques; including a list of recommendations about how to measure the impact of the outreach events, including the target audience and the staff involved. Also, for measuring the outcomes, it is added a list of techniques about how to know the best activities for each audience, understands the perception of the activity for the public and the application of quizzes based in QR technology for a quick outcome.
\end{abstract}

Keywords: Outreach, Science Education, Optics education, Informal Education, Outreach programs, Physics, International Day of Light

\section{INTRODUCTION}

Around the world there are many people doing science outreach activities but, in the end, measure the impact and the learning outcome results complicated. The present work includes a list of recommendations about how to measure the impact of the outreach events according to the experience of the group "Physics for everyone" of the Universidad Autonoma de Nuevo Leon, including the impact of the target audience and the staff involved.

"Physics for everyone" is a group formed in 2013 with the support of the Facultad de Ciencias Fisico Matematicas of the Universidad Autonoma de Nuevo Leon with outreach as the primary objective. As the founders are related to optics and photonics, a majority of workshops and activities of this group are related to those topics. The group is mainly formed of bachelor students and have much collaboration with other student clubs like the Theater, Robotics and Digital Art Student Clubs. This work was realized during the event "Suma Ciencia" in Monterrey, Nuevo Leon, Mexico; which is a bimonthly event and have different topics through the year and is held simultaneously in different states of Mexico through the "Recreacion en Cadena" (Mexican Network of Science Outreach Groups). In the "Suma Ciencia" of May, the national topic was the celebration of the International Day of Light.

"Physics for everyone" has done surveys but this is the first time the group is using alternatives to reduce the time making and capturing the survey. The event "Suma Ciencia" was the pilot of the tools proposed. A reason to use this event is that it has a formal education session for teachers and an informal session with the general public. The results have shown that the tools are scalable to take more surveys during the sessions. Also, during the formal session, the survey is taken as a play and is exciting to the user to answer the question. During the informal session, the survey was really quick to the user, and it didn't take much time, so the willingness to answer the survey may increase, because the attendants are pedestrians and, at least in this city, many people are in a rush even if they spend time inside the building of the event. It only took us, one volunteer, to spend 4 hours taking the surveys, and sometimes that help is needed elsewhere.

The formal session "Dumpster optics workshop" duration was 4 hours, from 09:00 to 13:00 hours, the surveys were taken at the start of the session, and due to lack of time it was not possible to apply a second survey at the end of the session. The informal session "Suma Ciencia IDL" event duration was 6 hours, from 15:00 to 21:00 hours, but the surveys started at 16:00. During this period, 44 surveys were done in a total of 37 minutes 41 seconds, and from the question, all of them marked they will return to this event.

Further author information: (Send correspondence to G.S.G)

G.S.G.: E-mail: guillermoesanchez@outlook.com,

P.V.G: E-mail: marlene.viera.gzz@gmail.com

Optics Education and Outreach V, edited by G. Groot Gregory, Proc. of SPIE Vol. 10741, 107410N

(c) 2018 SPIE · CCC code: $0277-786 X / 18 / \$ 18 \cdot$ doi: $10.1117 / 12.2320330$

Proc. of SPIE Vol. 10741 107410N-1 


\section{DESCRIPTION OF THE EVENT AND SURVEYS}

\subsection{Suma Ciencia International Day of Light}

The event "Suma Ciencia IDL" was divided into 2 sessions, one for formal based in "Dumpster Optics" ${ }^{3}$ and other for informal education based in project "Optics 4 every1". ${ }^{1}$ In the formal education, the attendees were teachers from elementary and secondary school. For the informal education, the attendees were mainly families walking around downtown and others followers from the facebook page.

The figure 1 shows the formal session, it shows teachers using the material for the chapter of shadows. Before this session, a survey was applied using the app Plickers ${ }^{\circledR}$ to gather the information. The survey applied was the "Beliefs About Science and School Science Questionnaire (BASSSQ)". ${ }^{2}$ The teachers had a good time answering the survey, and the answers were collected immediately. This app will be used in the future to gather more information. This first experience using the app was excellent and recommendable.

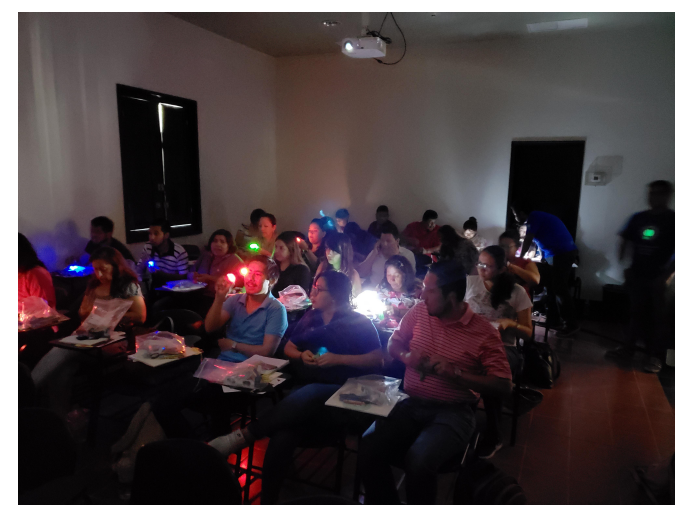

Figure 1. Dumpster optics in Mexico. This session was a formal education event focused on teachers at Monterrey, Mexico. This adapted version to Spanish of Dumpster Optics by Judith Donnelly. ${ }^{3}$

During the informal session, many resources were used to make it interesting to pedestrians, as the groups experience, a cartel or image is not enough. The figure 2 shows an excellent resource to promote the event on site, this is an old 3D technique using ChromaDepth ${ }^{\circledR}$ glasses and chalk; here, the Digital Art Student Club worked hard to draw something allusive to the International Day of Light. This work attracted many pedestrians to the main event that was inside the building. A lot of this kind of resources are used to promote the events, as a water rocket or even mimes, specifically this was really cheap and very attractive, and it teaches about the stereoscopic vision and invite to the pedestrians if they want to learn more of how it works they can visit other stands as shown in figure 3. This stand can be a beneficial activity due to is not expensive, is impressive and have an educational purpose.

The figure 4 shows another student group, the Theater Student Club "Laboratorio Kabblam". This show something that is working well in the group, the collaboration, some of these students are not studying physics or optics directly, but they have the willingness to help and show some material related with optics and photonics. Since the group collaborates with other groups as the Digital Art Student Club and the Theater Student Club were both groups have benefits, both have increased the people reached and the number of public activities performed of the year, but also, experience to reach people, see people reactions and what is more interesting to people.

During the informal session, there was a room full of neon lights as shown in figure 5, this particular room was inspired by an activity performed at the International Year of Light Closing event. This room was filled with neon lights, and people stayed there for a long time, there was only one entrance from this room, and there were chairs for the parents. Kids loved this activity and stayed there for an extended period playing with neon lights, some of them were artistic. This session had many pictures not showing in the figures. This activity was expensive compared with other activities but was the most liked activity, and many people were in line to enter the room. The group usually do an expensive but attractive activity everyone wants to do, usually, in 

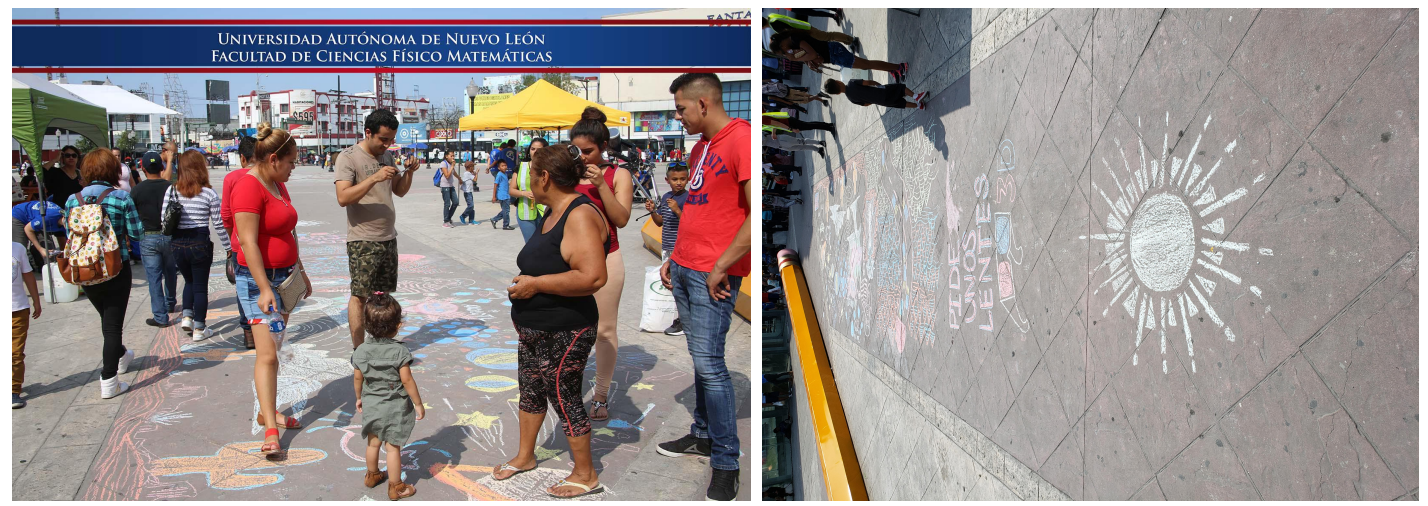

Figure 2. The group proposed a simple and fascinating activity outside the building. The collaboration with The Digital Arts Student Club, they draw with chalk outside the building an optics-related image to use with ChromaDepth ${ }^{\circledR}$ glasses. Many people ask for glasses because the volunteers draw the indication with chalk; also the staff was identified with vests. This stand is a low-cost, great impact activity to fascinate pedestrians and invite them to the modules inside the building.

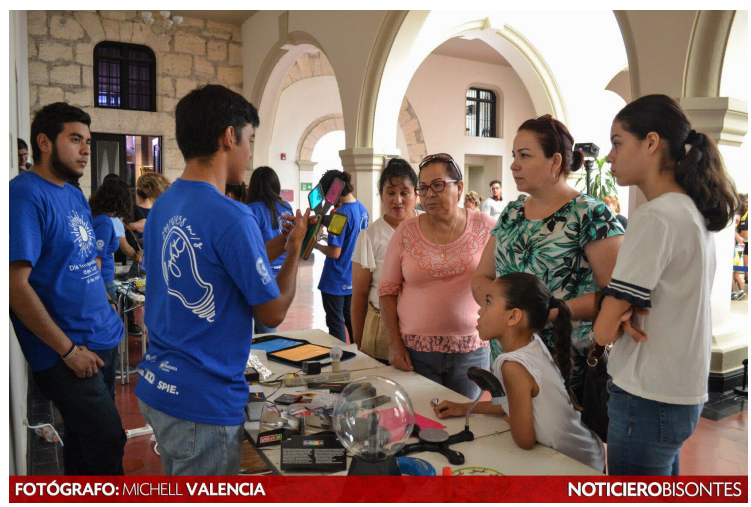

Figure 3. The event was divided into stands. The building has a much longer space to distribute visitors, so the event had specific modules. However, keep in mind the objective of the event, although the use other material not related with optics, the modules are related in a way the visitor can go from the basic to complex topics as they walk inside the building.

the groups' events, there is something unique even if is expensive, this guarantees a fan, and maybe he or she will return to the public events.

In summary, promote the event with a STEAM activity, doing so will reach many people. Collaborate with other groups, even if they are not related to optics or photonics. Make an artistic or inspiring stand that everyone wants to visit.

\subsection{Surveys}

There were two kinds of surveys applied, one for formal and other for informal education. This event is not the first time the group does surveys on the events. The primary objective was to reduce the time spent in a survey and reduce the time capturing the answers because in the past the group tried different methods and it took much time doing and capturing the answers. The table 1 show both surveys achieved this.

For the formal education, the app Plickers ${ }^{\circledR}$ was used. This free application is based on personalized QR codes that identify each student, to answer, the student shows the code oriented on one of 4 sides, each side is an option, and the teacher reads the QR code with the application. The QR codes were printed, gave them to the teachers and then the survey was applied. This survey was anonymous, this is, only the card number is shown.

For the informal education survey, the group used another app, QuickTapSurvey, and was made person to person. This app is restricted with basic usability in the free version. This survey was used to detect the feelings 


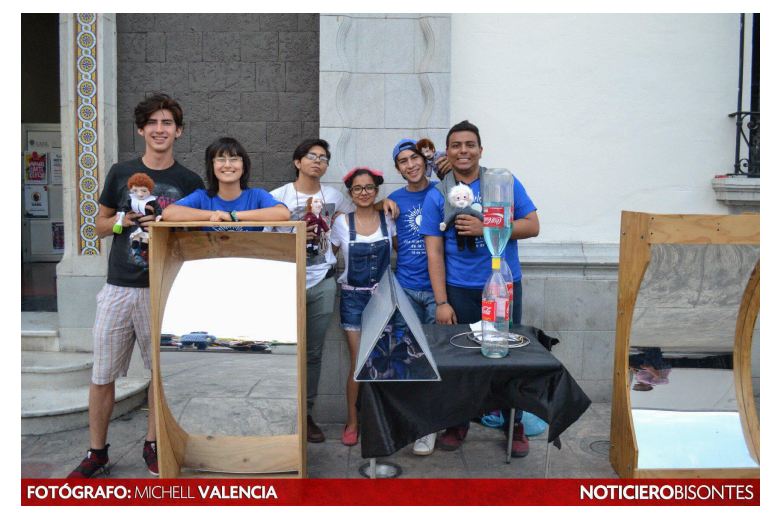

Figure 4. The group collaborates with other groups. This image shows a few members of the theater club, although they do not study optics, they can act, talk, invite pedestrians so easily and naturally to the event and they have the willingness to help in the events. Here, the group supply the mirrors and other materials, and the club loves the material and the reaction of the people.

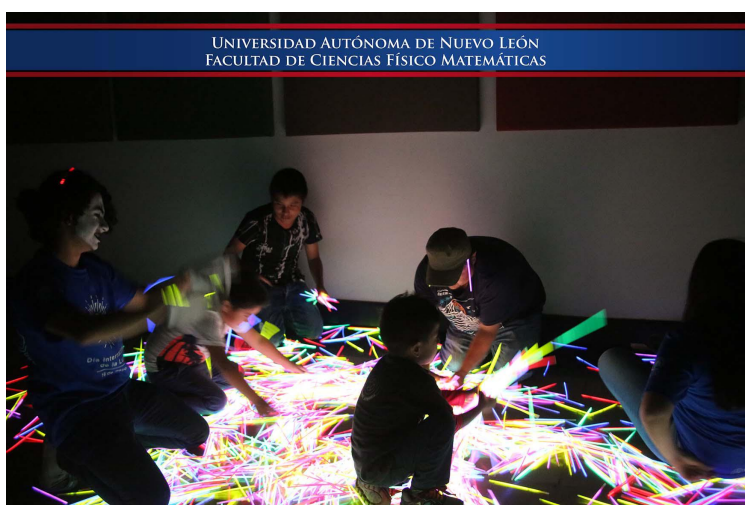

Figure 5. Neon lights. An activity to everyone is something the attendants can play with like the neon lights. This was a significant activity inspired by an event at the closing of the International Year of light 2015.

of the attendants at the end of the event and measure what they think of the stands. The objective of this session was to teach optics, and the survey directly asks if they think they learned something.

Another feedback not reported is a survey person to person on the staff. This feedback is required to know the feelings of the staff, if they are comfortable with the activity, how they see the attendants reaction and what they can upgrade to the activity. The informal interview is a must to do and give great feedback to improve the activities, sometimes the upgrade implies costs but reduces the time the people spend in the stands and give the opportunity to reach more people in less time. Also, use the photos and videos of the event to see attendants reactions and the stands that have more affluence. Usually, the activities that have more reactions are the diffraction grating lenses, plasma ball, and electromagnetism; these are the favorites by the attendants and the staff. This measure is unreported because the staff is voluntary and they can have the feeling that they are being evaluated.

\section{RESULTS AND COMMENTS}

The figure 6 show the results of the perspective of the event. This survey contains the question "I think the event was...", with this the perspective of the event, in general, is obtained. If they think the stands are funny or exciting or surprising, primarily to see if the primary objective of the event was achieved or if the activities need improvement to make them less funny or bored and more exciting.

The figure 7 show the results of the feelings after the event. In this survey the Likert question "I had fun", "I think is interesting", "I learned something" and "I like science" were asked to know how they feel after the 
Table 1. Survey information. It took less than 1 minute per person to answer a survey of 7 Likert questions. Moreover, the formal education can receive easily up to 63 surveys instead of 36 at the same time.

\begin{tabular}{|l|l|l|l|}
\hline Type & Surveys & Time taken & Questions \\
\hline Informal & 44 & $37: 41$ minutes & 7 \\
\hline Formal & 36 & 12 minutes & 21 \\
\hline
\end{tabular}

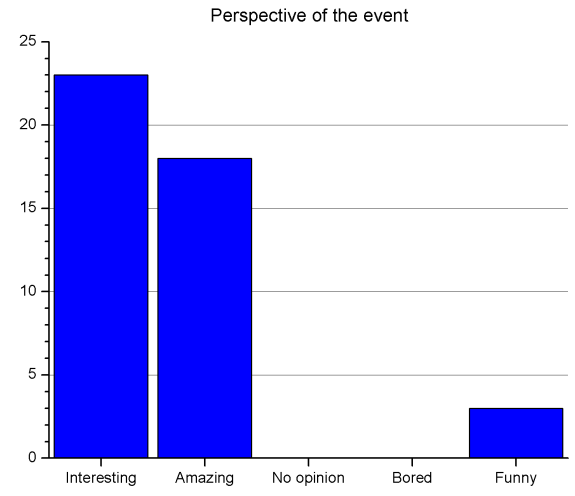

Figure 6. The peoples' perspectives of the event. This figure shows the results of 44 surveys. Most of the people think the event is interesting or amazing. These results give us feedback to improve the stands, none of the surveyed think it was boring or have no opinion about it. Only a few think it was funny.

event. Most of them gave us positive reactions. Between the reactions expected are if they think they learned something, the survey does not ask what they learned or ask a rigorous question about optics, it only shows they feel like they learned something. With this feedback, we can know if the attendees are willing to learn, and we can give more specific learning outcomes.

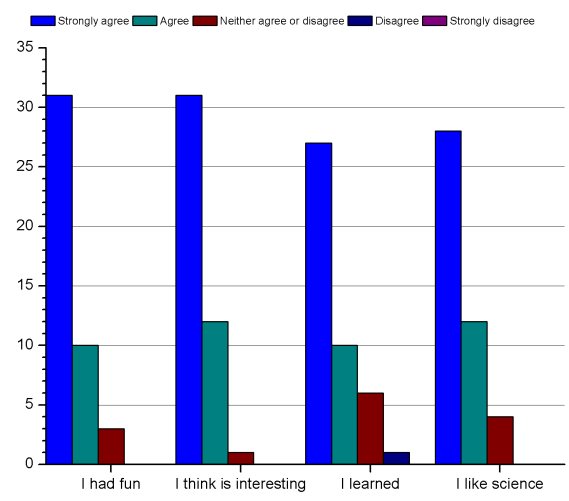

Figure 7. Feelings about the event.

In the informal education survey, one person was doing the survey, and the peak of the answers was nearly at the middle of the event because usually, a person spends more than an hour and a half inside the building. The figure 8 show this behavior and it will be taken as a count for future events. The total of attendees was around 1200, and the total of surveys represent around the $3 \%$.

With all this information in the pilot test, a more detailed survey will be included, with questions about specific knowledge the stands want to transmit to people. Using a survey in the future can help to understand the specific learning outcomes will be evaluated. 


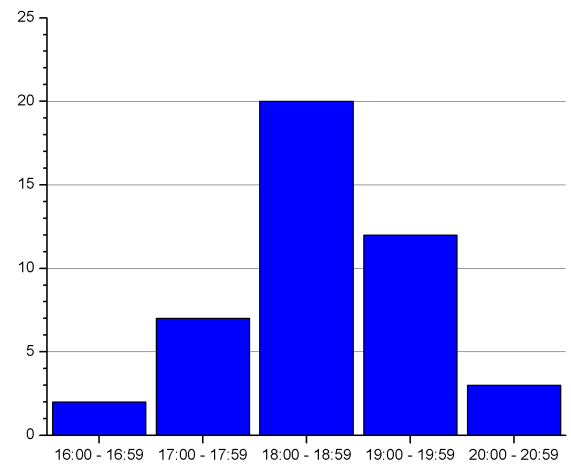

Figure 8. Best hours to take surveys are in the middle of the event.

\section{ACKNOWLEDGMENTS}

This work and all the outreach research is possible due to the help of a lot of people and organizations. The authors would like to thank the Facultad de Ciencias Físico Matemáticas and the SPIE for all the support given through the last years. To Judy Donelly and her great work with Dumpster Optics, which is a great course to teach optics with inexpensive materials. To all the students and students groups related to this paper, all the hard work and outreach is made by them.

\section{REFERENCES}

[1] Viera-González, P. M. and Sánchez-Guerrero, G. E., "'Optics 4 every1", the hands-on optics outreach program of the Universidad Autonoma de Nuevo Leon," 994615 (sep 2016).

[2] Aldridge, J., Taylor, P., and Chen, C.-c., "Development, Validation and Use of the Beliefs About Science and School Science Questionnaire (BASSSQ)," National Association for Research on Science Teaching , 1-15 (1997).

[3] Donnelly, J., Magnani, N., and Robinson, K., "Dumpster Optics: teaching and learning optics without a kit," 99460G (sep 2016). 